\title{
Research on Ethanol-gasoline Blended Fuel in Automotive Gasoline Engine
}

\author{
Jing-bo YU \\ Marine Engineering College \\ Dalian Maritime University \\ College of mechanical and power engineering \\ Dalian Ocean University \\ Dalian, Shahekou District, P.R.China
}

Lan-ying ZHAO

College of mechanical and power engineering

Dalian Ocean University

Dalian, Shahekou District, P.R.China

\author{
Shu-lin DUAN* \\ Marine Engineering College \\ Dalian Maritime University \\ Dalian, Ganjingzi District, P.R.China \\ e-mail: duanshulin099@yahoo.com.cn \\ www.dlmu.edu.cn
}

\section{Wen-xiao ZHANG}

College of mechanical and power engineering

Dalian Ocean University

Dalian, Shahekou District, P.R.China

\begin{abstract}
Global Energy and Environmental Issues have enhanced the development of new energy vehicle. The purpose of this study is to model and analyze the performance and exhaust emissions of a four-stroke SI engine operating on ethanol-gasoline blends of E80, E85 and E90 with the aid of AVL-BOOST. A model has been developed in an engine cycle to simulate the engine using ethanol and gasoline blends as fuels. With working characteristics of the model have been calculated, the study of variable parameters is carried on the engine which is fueled with ethanol gasoline blends. Under the working condition of max torque, the influences of compression ratio, the ignition advance angle and the intake valve closing angle are simulated and analyzed for three kinds of fuel material. At the same time a final engine performance is analyzed. It provides reference for structural optimization of gasoline engine and further three dimensional numerical calculations.
\end{abstract}

Keywords-Automobile; Ethanol and gasoline; Environment; optimal design; Simulation.

\section{INTRODUCTION}

With global economy boost, China's automobile industry is also under rapid development. The need in transportation and car ownership has grown tremendously which aggravate the depletion of natural fuel and endanger the environment. Air pollution caused by vehicle emissions has become the primary source of pollution in major cities and is threatening human health. To solve this issue, the development of vehicles using new energy has become inevitable for future automobile industry. Ethanol which is an oxygen-rich fuel (oxygen content of $38 \%$ ) is gaining increasing popularity as an alternative fuel. When ethanol is mixed with gasoline in a proper ratio, gasoline can be burnt more completely in the cylinder, which can not only effectively reduce the needed amount of gasoline, but also significantly reduce $\mathrm{HC}, \mathrm{CO}$, and other emission gases[1,2]. Therefore, a further investigation of the relationship between engine structural and operational parameters and the performance of blended fuel would be crucial in promoting the use of ethanol blended fuel and reducing air pollution.
Based on the gasoline engine with single gasoline fuel, AVL-BOOST commercial software is used to carry out thermodynamics calculation of ethanol gasoline flexible fuel E85, E90 and E95 on a 4-cylinder engine, to forecast the performance and optimize the structural parameters of the gasoline engine. The data foundations can be used to get the further optimization of the engine performances $[3,4]$.

\section{THE ESTABLISHMENT OF THE CALCULATION MODEL}

The calibration of gasoline engine should be carried out first. On the basis, a simulation model for the using ethanol fuel engine is established. The original gasoline engine simulation model is shown in Figure 1. Air enters the cylinder $(\mathrm{C} 1, \mathrm{C} 2, \mathrm{C} 3$ and $\mathrm{C} 4)$ from the ambient boundary (SB1) of the air intake system, through the inlet pipe $\rightarrow$ the air filter (CL1) $\rightarrow$ the inlet (PL2) $\rightarrow$ the exhaust gas through the exhaust passage $\rightarrow$ exhaust pipe $\rightarrow$ catalyst (CAT1) $\rightarrow$ main and subordinate silencers (PL3 and PL4) flow out of the ambient boundary of the exhaust system. In addition, 11 14 is the four injectors; R1 R10 are used to adjust the flow coefficient in the pipelines, MP1 $\sim$ MP23 are points for the measurement.

With the establishment of the calculation, simulation data has been input to the model. First, the basic parameters of the simulation control, such as speed, air-fuel ratio, fuel properties, ignition sequence, the proportion of ethanol gasoline fuel, the engine friction work according to the empirical formula simulation results are given. Flow coefficient is from the results of airway bench test. The curve of the combustion heat rate is derived from the engine test measurements. The main parameters of the engine are shown in Table 1. 

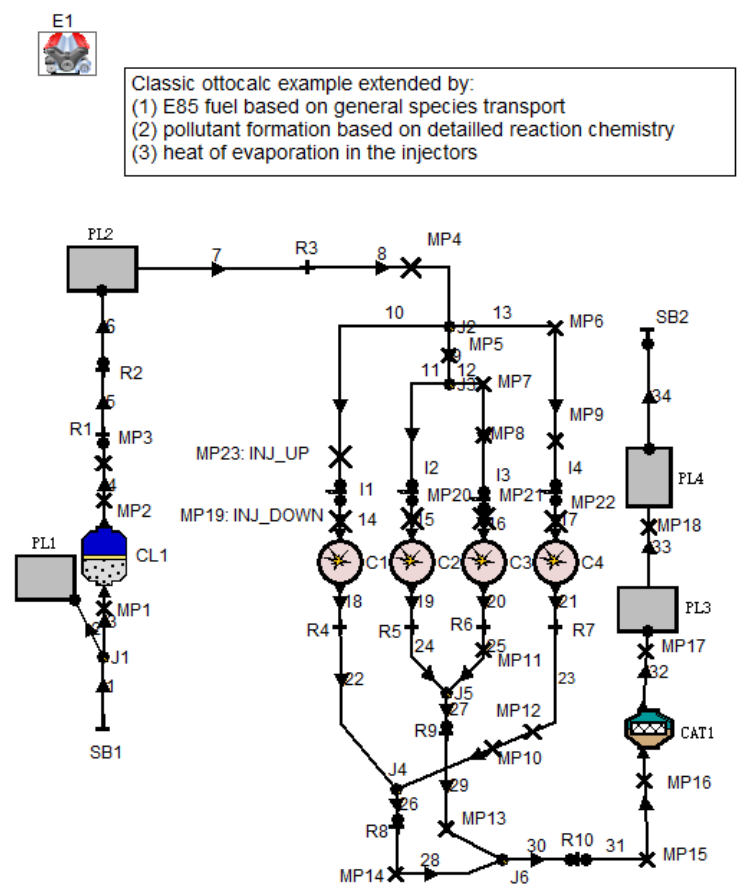

Figure 1. Simulation calculation model

TABLE I. MAIN SPECIFICATION FOR THE ENGINE

\begin{tabular}{ll}
\hline Working mode & Naturally aspirated \\
\hline Cylinder arrangement & Inline \\
Number of cylinders & 4 \\
& $1-3-4-2$ \\
Ignition order & 86 \\
Bore size $(\mathrm{mm})$ & 86 \\
Stroke $(\mathrm{mm})$ & 10.5 \\
Compression ratio & $106.4 / 6400$ \\
Maximum power $(\mathrm{kW} / \mathrm{rpm})$ & $178 / 4800$ \\
Maximum torque $(\mathrm{N} \cdot \mathrm{m} / \mathrm{rpm})$ &
\end{tabular}

To set the parameters of the model components is very important to build the model. Th90e VIBE 2 ZONE combustion model and the double Weber function are selected to calculate the gaseous state of the combustion products (e.g, the burned zone) and the remaining freshly charged state (e.g, unburned zone). The heat release rate is determined by equation(1).

$$
\frac{d m_{b}}{d t}=\frac{m_{e}-m_{b}}{\tau_{b}}
$$

Where, $m_{b}$ - The total mass of burned,

$m_{e}$ - The mass of the inhalation flame, $\tau_{b}$ - The characteristic combustion time (i.e. the time required to burn a single turbulence).

The Woschni 1978 model is used for the heat transfer model, and the equation (2) is outlined below.

$$
\alpha_{w}=130 \cdot D^{-0.2} \cdot p_{c}^{0.8} \cdot T_{c}^{-0.53} \cdot\left[C_{1} \cdot c_{m}+C_{2} \frac{V_{D} \cdot T_{c, 1}}{p_{c, 1} \cdot V_{c, 1}}\left(p_{c}-p_{c, 0}\right)\right]^{0.8}
$$

In the formula, $C_{1}=2.28+0.308 \cdot c_{u} / c_{m}$

For DI engines $\mathrm{C} 2=0.00324$, for IDI engines $\mathrm{C} 2=$ 0.00622 ,

D - Cylinder diameter,

$C_{m^{-}}$- Average piston speed,

$C_{u}$ - Peripheral velocity,

$V_{D}$ - The volume of displacement per cylinder,

$P_{c, o}$ - Engine cylinder pressure [bar],

$T_{c, l}$ - In-cylinder temperature when intake valve is closed, [bar].

$P_{c, 1}$ - In-cylinder pressure when intake valve is closed

With the establishment of the model, the original gasoline engine model has been calibrated, and the test results and the simulation results have been used to draw the dynamometer diagram in the whole speed range and compare them. The results show that the two curves are basically consistent, the curves are consistent basically. While the simulation and the measured results are between the relative error of $5 \%$ or less. Considering the use of various simplified conditions and assumptions in the modeling process, as well as the measurement error of the test instrument itself, the established engine working model is quite successful. Therefore, the model can be applied to further predict the performance of ethanol-gasoline flexible fuel engine and optimize the design of operating parameters.

\section{ENGINE PERFORMANCES PREDICTION}

\section{A. Effect of Ethanol Gasoline Characteristics on Gasoline Engine External Characteristics}

Air and fuel are fixed into the cylinders during the working process as the working matters. To simplify the problem, it has been assumed that the air consists mainly of oxygen and nitrogen [5]. Fuel is a mixture of gasoline and ethanol fuel, in which the chemical composition of ethanol is $\mathrm{C} 2 \mathrm{H} 5 \mathrm{OH}$, the main component of gasoline is $\mathrm{C} 8 \mathrm{H} 15.1$. The fuel component mass fraction and its properties directly affect the combustion quality. And the following study is about the engine performances with E80, E85 and E90 ethanol gasoline fuel respectively. 

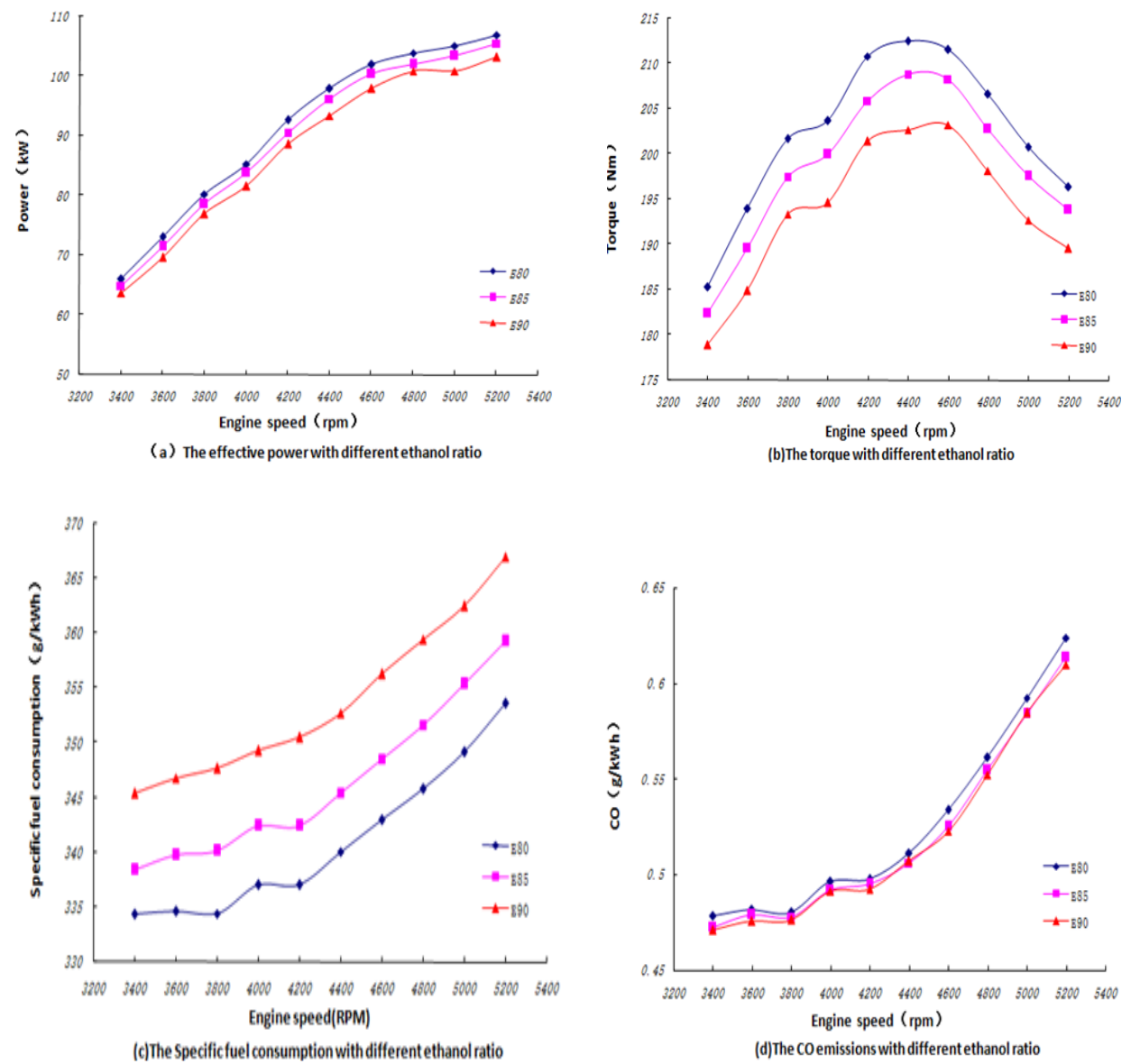

Figure 2. Effect of different ethanol ratio on the engine performances

Without any structure change in the gasoline engine. The impacts on the gasoline engine performance by the ethanol content are shown in Figure 2. With the increase of the ethanol content in the fuel, the external characteristic power and torque decreases obviously, and the power performance becomes worse. But the economy and emissions of the gasoline engine are improved. Therefore, the need to use ethanol gasoline based on the engine operating parameters are optimized to compensate for lack of engine power [6].

\section{B. Compression Ratio on the Engine Performances}

The compression ratio of the engine is the most important structural parameter which affects the performance index of the gasoline engine. Improving the compression ratio of the engine can improve the power and economy of the gasoline engine. The higher the compression ratio, the higher the thermal efficiency will be. But with the increase of compression ratio, thermal efficiency growth rate is getting smaller and smaller. Compression ratio increases so that the compression pressure, the maximum combustion pressure are increased, so as the engine mechanical efficiency. When the gasoline engine working at a high compression ratio, the deflagration will happen and it is not good for engine. To improve the power by increasing the compression ratio should avoid having a deflagration phenomenon occurred. The maximum torque corresponding to the speed of $4500 \mathrm{r} / \mathrm{min}$ is the calculation point. At this speed, the others model parameters should not be changed during the process of the compression ratio changing. The change rate of compression (0.2 in step) is selected to simulate the working process. The influence of compression ratio on engine performance and emissions was analyzed in the following. 


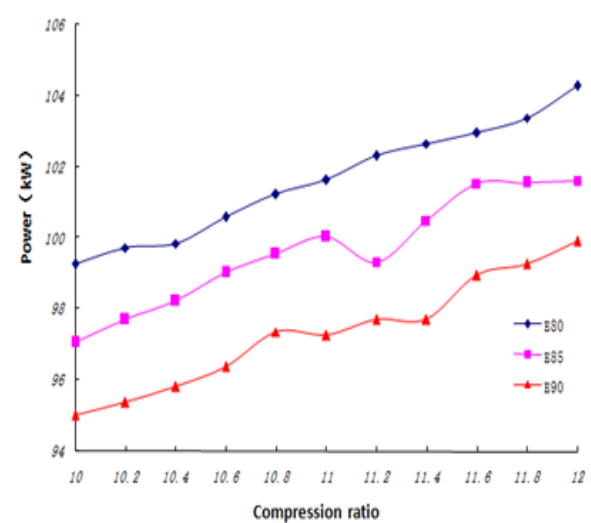

(a) Effect of compression ratio on the effective power

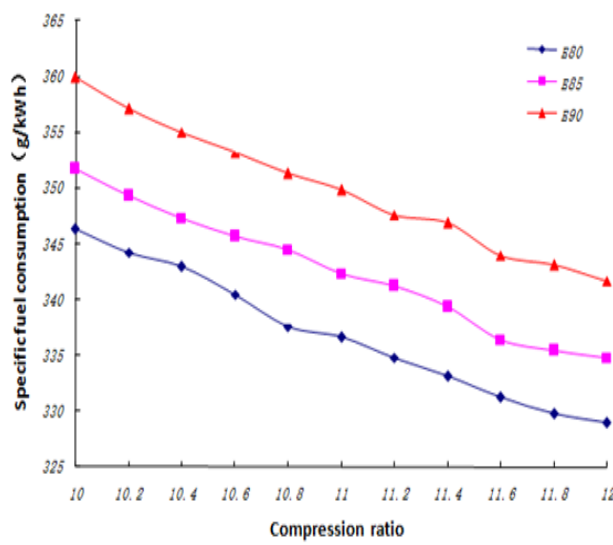

(c) Effect of compression ratio on the specific fuel consumption

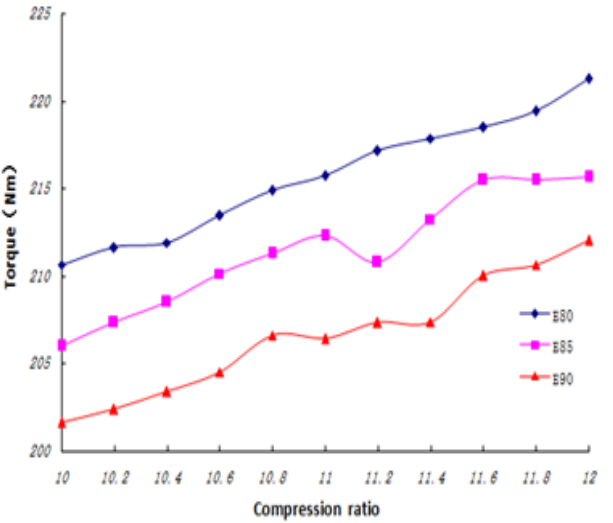

(b) Effect of compression ratio on the torque

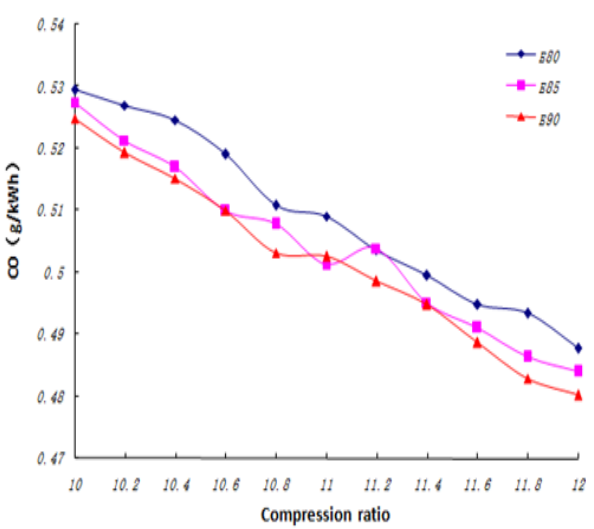

(d) Effect of compression ratio on the $\mathrm{CO}$ emissions

Figure 3. Effect of compression ratio on the engine performances

The compression ratio effects on the ethanol fuel engine performance are shown in figure 3. As the compression ratio increases, the engine power and torque increases, fuel consumption and $\mathrm{CO}$ emissions are decreasing $[7,8]$. This is mainly due to the compression ratio is increased, the compression generated by the cylinder pressure and temperature relative increase. The mixture of gas molecules in the gasification becomes more completely and getting more finer particles. Coupled with the effect of eddy current and turbulence, the fuel and the air are mixed more evenly. All of these can make the mixture burn quickly, and get higher thermal efficiency, more power. The economy and emissions performance will been improved as well. In addition, as the compression ratio increases, the engine will tend to increase the knock, so the compression ratio can not be infinitely increased for the engine structural strength and work performance constraints.

\section{Ignition Advance Angle on the Engine Performances}

The ignition advance angle is one of the main operating factors of the engine. and an appropriate ignition advance angle plays an important role in the engine's dynamic performance, economic performance and emissions. when the gasoline is mixed with ethanol, the oxygen content of mixed fuel is increased greatly, which makes the combustion in cylinders become more quickly and completely. So the ignition advance angle can be postponed properly. On the other hand, ethanol gasoline can increase the octane number of mixed fuel, and fuel anti-explosive is improved. Which allows to select an appropriate advance ignition angle because of its high octane number of ethanol (RON110). $4500 \mathrm{r} / \mathrm{min}$ is set as the engine speed at the maximum torque point in the model. The ignition advance angle $\left(2{ }^{\circ} \mathrm{CA}\right)$ is changed from $-19 \sim-5^{\circ} \mathrm{CA}$ to simulate the engine operating process. Next, the influence of the ignition advance angle on the engine performance and emissions will be analyzed. 

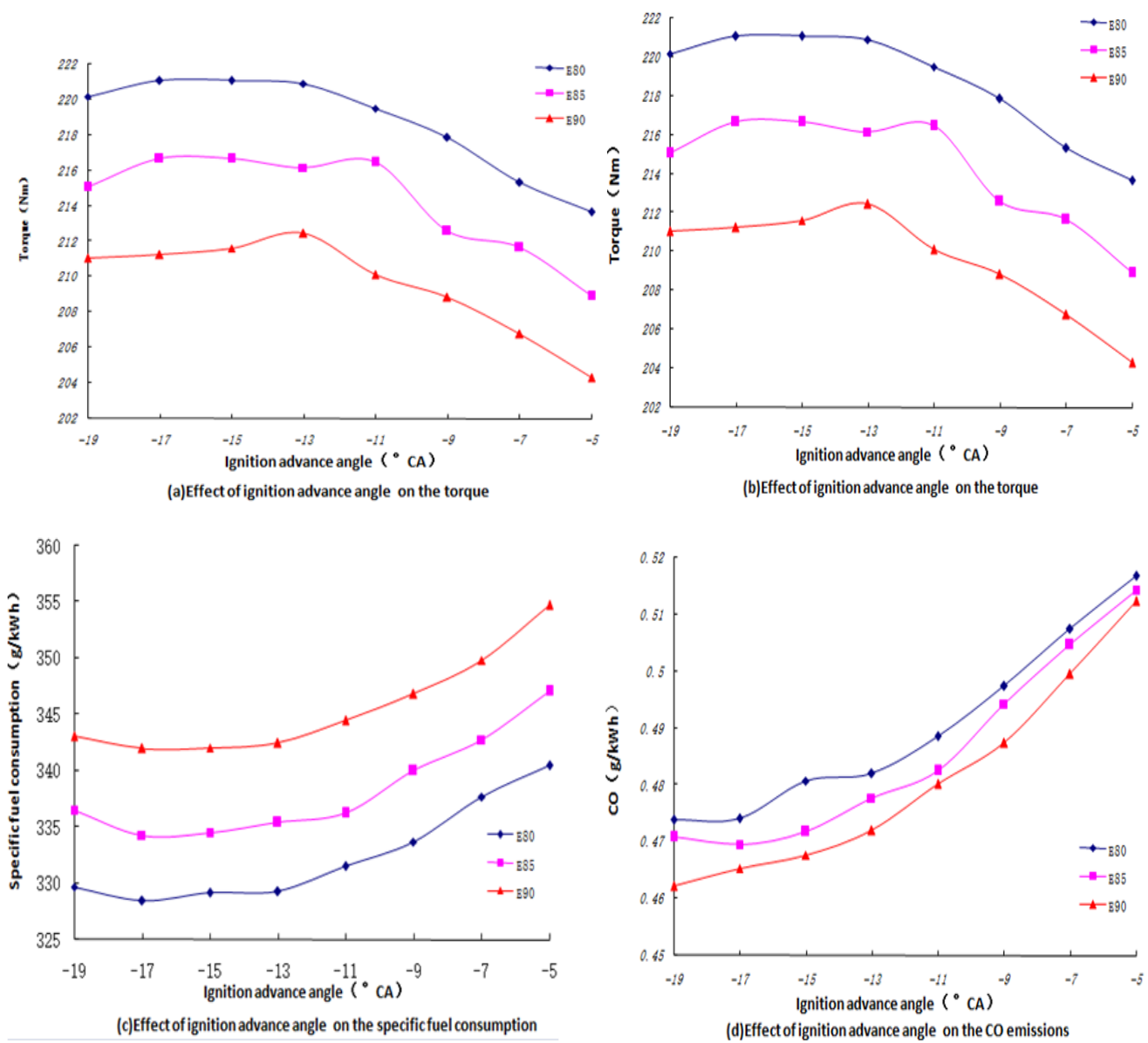

Figure 4. Effect of ignition advance angle on the engine performances

From the results of the calculations, it is easy to know that the ignition advance angle have a great impact on the power and economy of the engine. With the increase of the ignition advance angle, the dynamics of ethanol gasoline increased significantly, the specific fuel consumption is decreased with the increase of the ignition advance angle first and increased slightly after a while. At the same time, the $\mathrm{CO}$ emissions decreases significantly.

\section{The Impact of the Intake Delayed Angle on the Engine Performances}

When the gasoline engine piston reaches the bottom dead center, the intake valve is not closed immediately. It will be closed after a crank angle over the bottom dead center. This lag angle becomes the intake valve retardation angle. In this crank angle, although the piston is moving up, but the air flow speed is still high through the intake system. So the fresh air flows into the cylinder with the aid of inertia continually. Thus, it is possible to make the cylinder pressure equal to or slightly higher than the intake pipe pressure at the end of the intake process. To keep the other parameters unchanged, and the engine speed at 4500 $/ \mathrm{min}$, we can change the engine valve closing angle only in the model. In this paper, six kinds of ignition advance angles $\left(5^{\circ} \mathrm{CA}\right)$ in 5 $30^{\circ} \mathrm{CA}$ interval will be selected to simulate the process of the engine. The influence of intake delayed angle of intake valve on engine performances and emission is analyzed. 


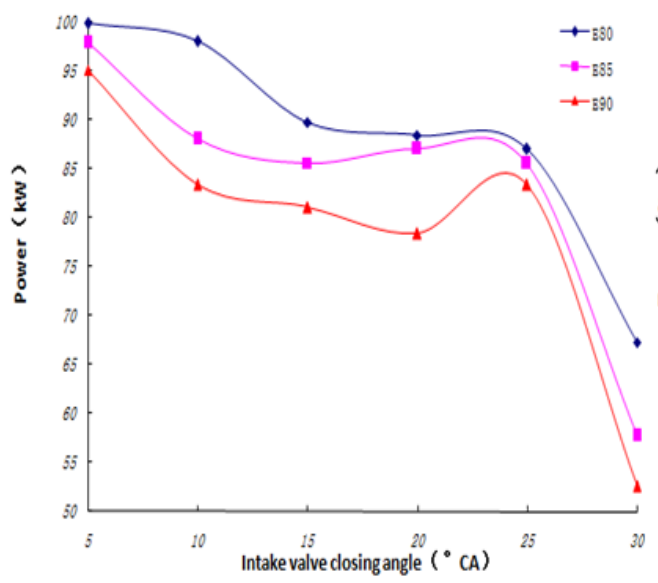

(a) Effect of intake delayed angle on the effective power

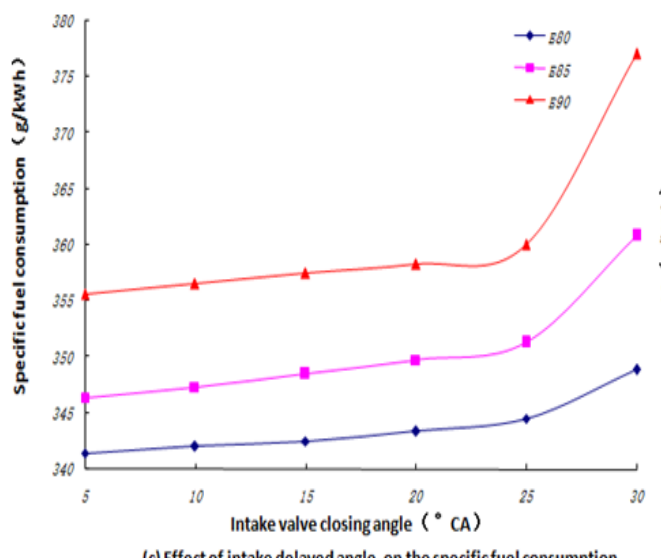

(c) Effect of intake delayed angle on the specificfuel consumption

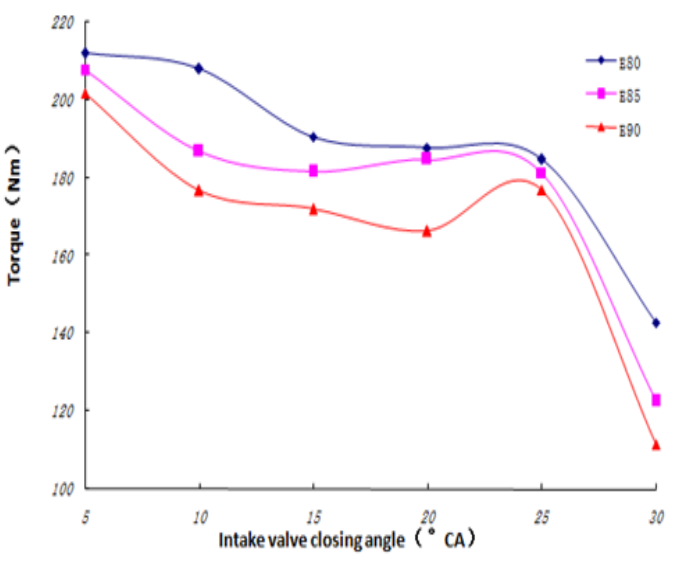

(b) Effect of intake delayed angle on the torque

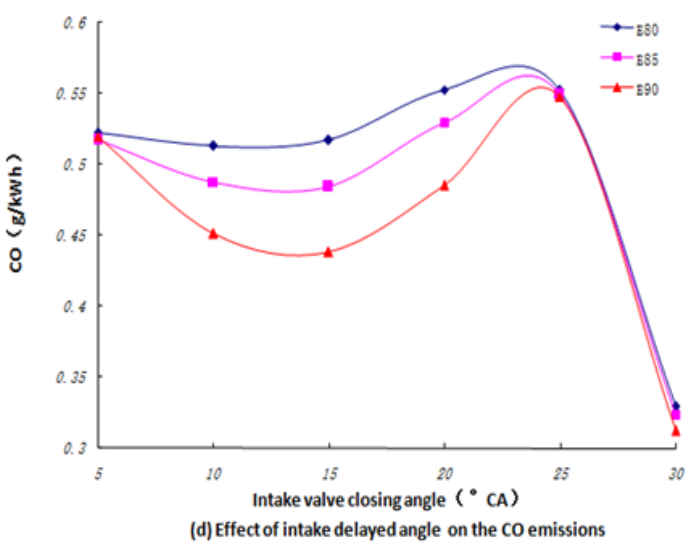

(d) Effect of intake delayed angle on the $\mathrm{CO}$ emissions

Figure 5. Effect of intake delayed angle on the engine performances

The curves of power, torque, fuel consumption and $\mathrm{CO}$ emissions are shown in Figure 5. At the same speed, different intake air delayed angles corresponding to the inflation efficiency, torque and fuel consumption rate are not same. The torque and inflation efficiency of the engine first increase and then decrease, and the fuel consumption rate decreases first and then increases, and the maximum torque and the minimum fuel consumption rate are obtained in the variation range of the inlet closing angle. The corresponding intake air delay angle is different. Comparing the results of three different fuel ratios, it can be seen that the optimal angle of divergence of the inlet air is different, and the optimum retarding angle for the large proportion of ethanol gasoline moves forward.

\section{E. Multi - Parameter Simulation and Optimization of Engine Working}

The single-parameter study of the engine's working process is carried out by using the established model. The performance of the engine with the parameters studied have been analyzed. These simulations are carried out within the range of single parameters, which can only reflect the change of the engine performance under these single parameters, and can not fully reflect the interaction between the parameters. It is difficult to determine the coupling effect of each parameter to get the best performances of the engine. When the engine model is established, the AVL-BOOST and ISIGHT are used to optimize the multi-parameter of the engine when the E90 fuel is used at $4500 \mathrm{r} / \mathrm{min}$. In the simulation, several parameters are used as optimization variables to determine the target function, to obtain the coupling of multiple parameters under the engine's optimal dynamic performances.

In the process of optimization, we usually choose the parameters which have great influence on the objective function as the optimization variables. The dynamic performances of the engine is affected by many factors, but each factor affects the way and influence degree is different. Compression ratio on the engine performance has a one-way, that is, in the allowable knocking conditions and environmental conditions, the engine's main performance with these parameters increases. As the machine is a variable valve timing engine, the final compression ratio is identified as 10.5. and in the change range of ignition advance angle and intake delayed angle, the engine's dynamic performances can get the best value. The ignition advance angle and the 
intake delayed angle are taken as the independent variables to optimize the engine performances. Considering the influence of these two parameters on the range of parameter variation, the optimization range of ignition advance angle is extended to $-25 \sim-2{ }^{\circ} \mathrm{CA}$, the optimal range of the inlet valve closing angle is set to $2 \sim 35^{\circ} \mathrm{CA}$.

After 237 cycles, the optimization results are converged. When the ignition advance angle is $-22^{\circ} \mathrm{CA}$ and the intake air delay angle is $18{ }^{\circ} \mathrm{CA}$, the maximum output power of the engine is $100.8 \mathrm{~kW}$. This shows that the working process of the engine is a multi-parameter mutual coupling process, to seek the best performance of engine performances indicators should take into account a wide range of factors.

\section{CONCLUSIONS}

- AVL-BOOST software can be used to obtain the performances of engine with different proportion of ethanol gasoline. With analyzing and researching these results, it can provide efficient and reliable reference for engine performances optimization, also can save a lot of time and cost.

- The calculation and analysis of the engine working process and the optimization calculation under the multi-parameter coupling can deepen the understanding of the effect of this parameter, and guide the calibration of the engine, so as to promote the development of new energy vehicles and environment.

\section{ACKNOWLEDGMENT}

This work is supported by the general project of Liaoning province department of education (L2015088), the course construction project of Dalian Ocean University (KC2014KQ12).

\section{REFERENCES}

[1] G. Najafi et al. Performance and exhaust emissions of a gasoline engine with ethanol blended gasoline fuels using artificial neural network [J]. Applied Energy, 2009,86:630-639.

[2] Al Hasan M. Effect of ethanol - unleaded gasoline blends on engine performance and exhaust emission [J].Energy Conversion and Management, 2003(9): 1547-1561.

[3] Wei-Dong Hsieh. Engine performance and pollutant emission of an SI engine using ethanol - gasoline blend fuels. Atmospheric Environment [J].Volume36, Issue3, January2002, Pages403 410.

[4] Alzueta M.U, Hernández J.M. Ethanol Oxidation and Its Interaction with Nitric Oxide[J]. Energy\& Fuels, 2002, 16(1): 166-171.

[5] Liu Fangjie, Liu Peng, Zhu Zan, et al. Regulated and Unregulated Emissions from a Spark Ignition Engine Fueled with Low-Blend Ethanol-Gasoline Mixture [J]. Proceedings of the institution of mechanical engineering part D: Journal of Automobile Engineering,2012, 226(D4): 517-528.

[6] Qi Donghui, Liu Shenghua, Li Hui, et al. Experimental Investigation on an EFI Engine Fueled With Gasohol Blend[J]. Chinese Internal Combustion Engine Engineering, 2007, 28(2) : 27-30.

[7] Balki M.F, Sayin C, Canakcic M. The Effect of Different Alcohol Fuels on the Performance, Emission and Combustion Characteristics of a Gasoline Engine[J]. Fuel, 2014,115 (1): 901-906.

[8] Hsieh WD, Chen RH, Wu TL, et al. Engine Performance and Pollutant Emission of an SI Engine Using Ethanol-Gasoline Blended Fuels[J]. Atmospheric Environment. 2002, 36(3): 403-410. 